\title{
Smoking and Sleep Position are only Pieces of the Puzzle Resulting in The Sudden Infant Death Syndrome
}

\begin{abstract}
A review of: Schwartz PJ, Priori SG, Dumaine R, Napolitano C, Antzelevitch C, Stramba-Badiale M, Richard TA, Berti MR, Bloise R 2000 A molecular link between the sudden infant death syndrome and the long-QT syndrome. N Engl J Med 343: 262-267.
\end{abstract}

Qudden Infant Death Syndrome $\checkmark$ (SIDS) is the most common cause of death during the first year of postnatal life with a peak incidence between 2-4 months of age. In spite of the fact that SIDS has been recognized since biblical times, its precise etiology and pathogenesis remains elusive.

SIDS is a multifactorial disorder that is influenced by environmental, epidemiologic, and biologic risk factors. A decade ago, epidemiologic studies in New Zealand showed a definite relationship between SIDS and the sleeping position of an infant (1), which immediately received worldwide attention. Subsequent studies in Europe and the United States confirmed the finding that placing an infant in the supine position (on the back) while sleeping, in contrast to the prone or the sidesleeping position, significantly reduced the prevalence of SIDS. Although sleep position is not the cause of SIDS, it is certainly an important risk factor that may influence arousal responsiveness and cardiorespiratory control - physiologic functions thought to be associated with SIDS. Following a series of 'back-to-sleep' programs in Great Britain and the United States, SIDS rates in both countries have declined by approximately 50\%. Public awareness of the 'safe' sleep position for infants as a factor in preventing SIDS has stimulated a renewed interest in understanding this common and tragic condition of infancy. More recently, a study completed in Bristol (2) confirmed that postnatal exposure to tobacco is also an important risk factor, perhaps due to the finding that a smoke-filled atmosphere potentiates hyperplasia of the neuroendocrine cells in the developing lung. The impact of these findings awaits a clinical trial that demon-

\section{Robert H. HaSlam}

strates the effectiveness of a smoke-free environment on the rate of SIDS.

In 1998, Schwartz and colleagues published the results of an electrocardiographic (EKG) study that determined the QT interval of 34,442 newborn infants (3). There were 34 deaths on follow-up at 1 year of life in this cohort and 24 were found to be the result of SIDS. The mean QT interval in the survivors was $400 \pm 20$ ms. as compared to $435 \pm 45 \mathrm{~ms}$. for those infants who died from SIDS and $393 \pm 24$ ms. for those who died of causes other than SIDS $(p<0.05)$. Of significance was the finding that none of the survivors, but $50 \%$ of the SIDS infants (12/24), had a prolonged QT interval greater than $440 \mathrm{~ms}$. These data led the authors to speculate that the long QT interval syndrome may play an important role in the cause of SIDS.

Recently, the Schwartz group reported the findings in a 6-week-old infant who almost died of SIDS (4). An EKG on admission to hospital showed ventricular fibrillation, and upon cardioversion, the QT interval was found to be $648 \mathrm{~ms}$. Subsequently, molecular studies of genomic DNA from the infant showed a spontaneous mutation of a cardiac sodium-channel gene (SCN5A) with the substitution of a single amino acid, asparagine for serine at codon 941 . There was no family history of SIDS and both parents had normal QT intervals. This report is noteworthy for the following reasons: 1) if the infant had died prior to the EKG, a diagnosis of SIDS would surely have been made, but the presence of ventricular fibrillation raised the possibility of the long QT syndrome; 2) treatment with beta-blockers has successfully prevented recurrent cardiac arrhyth- mias; and 3) the finding of a spontaneous mutation in an ion channel gene known to regulate ventricular repolarization in an infant with near-miss SIDS, taken with the finding that a prolonged QT interval is highly correlated with infant death, is compelling evidence that SIDS is directly related to the long QT syndrome.

The challenges which remain will be to ascertain the frequency of the long QT syndrome as a cause of SIDS, followed by additional studies which will determine the efficacy of EKG screening for long QT intervals during the first week of life and the effectiveness of beta-blockers in the prevention of SIDS in those infants at risk. In the future, new solutions to the problem of SIDS in this group of patients will result from determining the link between the mutation and the clinical pathophysiology.

1. Mitchell EA, Scragg R, Stewart AW, Becroft DM, Taylor BJ, Ford RP, Hassal JB, Barry DM, Allen EM, Roberts AP 1991 Results from the first year of the New Zealand cot death study. N Z Med J 104:71-76

2. Blair PS, Fleming PJ, Bensley D, Smith I, Bacon C, Taylor E, Berry J, Golding J, Tripp J 1996 Smoking and the sudden infant death syndrome: results from 1993-5 case control study for confidential inquiry into stillbirths and deaths in infancy. BMJ 313:195198

3. Schwartz PJ, Stramba-Badiale M, Segantini A, Austtoni P, Bosi G, Giorgetti R, Grancini F, Marni ED, Perticone F, Rosti D, Salice P 1998 Prolongation of the QT interval and the sudden infant death syndrome. N Engl J Med 338:1709-1714

4. Schwartz PJ, Priori SG, Dumaine R, Napolitano G, Antzelevitch C, Stramba-Badiale M, Richard TA, Berti MR, Bloise R 2000 A molecular link between the sudden infant death syndrome and the long-QT syndrome. N Engl J Med 343:262-267

Editor

Research News 